TITLE:

\title{
Up-regulation of miR-582-5p regulates cellular proliferation of prostate cancer cells under androgen-deprived conditions.
}

\section{AUTHOR(S):}

Maeno, Atsushi; Terada, Naoki; Uegaki, Masayuki; Goto, Takayuki; Okada, Yoshiyuki; Kobayashi, Takashi; Kamba, Tomomi; Ogawa, Osamu; Inoue, Takahiro

\section{CITATION:}

Maeno, Atsushi ...[et al]. Up-regulation of miR-582-5p regulates cellular proliferation of prostate cancer cells under androgen-deprived conditions.. The Prostate 2014, 74(16): 1604-1612

\section{ISSUE DATE:}

2014-08-29

URL:

http://hdl.handle.net/2433/198763

\section{RIGHT:}

This is the peer reviewed version of the following article: Maeno, A., Terada, N., Uegaki, M., Goto, T., Okada, Y.,

Kobayashi, T., Kamba, T., Ogawa, O. and Inoue, T. (2014), Up-regulation of miR-582-5p regulates cellular proliferation of prostate cancer cells under androgen-deprived conditions. Prostate, 74: 1604-1612, which has been published in final form at http://dx.doi.org/10.1002/pros.22877. This article may be used for non-commercial purposes in accordance with Wiley Terms and Conditions for Self-Archiving.; 許諾条件により本文ファイルは2015-08-29に公開.; This is not the published version. Please cite only the published version.; この論文は出版社版でありません。引用の際には出版社版 をご確認ご利用ください。 
The Prostate

\title{
Up-Regulation of miR-582-5p Regulates Cellular Proliferation of Prostate Cancer Cells Under Androgen-Deprived Conditions
}

\author{
Atsushi Maeno, Naoki Terada, Masayuki Uegaki, Takayuki Goto, Yoshiyuki Okada, \\ Takashi Kobayashi, Tomomi Kamba, Osamu Ogawa, ${ }^{*}$ and Takahiro Inoue \\ Department of Urology, Kyoto University Graduate School of Medicine, Kyoto, Japan
}

\begin{abstract}
BACKGROUND. MicroRNAs are noncoding small RNA that negatively regulate target gene expression by binding to the $3^{\prime}$-UTR of mRNA. Previous studies have shown that several microRNAs play a pivotal role in prostate cancer by acting as oncogenes or tumor suppressors. This study was aimed at identifying microRNAs that contribute to the progression to castration resistant prostate cancer.

METHODS. MicroRNAs expression profiles of a xenograft model and cell lines were examined by microarray analysis and real-time PCR. Functional analysis of miR-582-5p in cellular proliferation was examined by cell counting. Furthermore, in order to investigate a candidate target of miR-582-5p, microarray analysis and analysis in silico were utilized.

RESULTS. MiR-582-5p was identified to be up-regulated at the castration resistant stage of a xenograft model, KUCaP2 and in castration resistant cell line, AILNCaP\#1. Overexpression of miR-582-5p increased the number and the percentage of $S$ phase of LNCaP cells under androgen deprived condition. Moreover, suppression of miR-582-5p decreased the number and the percentage of $S$ phase of AILNCaP\#1 cells. Furthermore, we identified that miR-582$5 p$ down-regulates EFNB2 expression, which is down-regulated at the castration resistant stage of a xenograft model, KUCaP2 and in castration resistant cell line, AILNCaP\#1.

CONCLUSIONS. Our results suggest that up-regulation of miR-582-5p contributes to an increase in the proliferation of prostate cancer cells under androgen deprived conditions. Prostate (C) 2014 Wiley Periodicals, Inc.
\end{abstract}

KEY WORDS: $\quad$ miR-582-5p; prostate cancer; EFNB2; castration resistant

\section{INTRODUCTION}

MicroRNAs are non-coding small RNAs that function to regulate specific target mRNAs by binding to complementary regions in the $3^{\prime}$-UTR of their targets. These molecules have been shown to be involved in various biological processes, including proliferation, apoptosis, differentiation, and development. A number of microRNAs have been reported to play a crucial role in cancers by acting as oncogenes or tumor suppressors [1-3]. In prostate cancer, alterations in the expression profiles of microRNAs have been reported, and some microRNAs have been demonstrated to play a role in the progression of castration resistant prostate cancer (CRPC) [4-6].

Most patients with prostate cancer progress to CRPC after initial response to androgen deprivation therapy. Although multiple hormonal therapies may increase the time to progression, subsequent therapies in men with CRPC, including the chemotherapy, docetaxel have limited benefit [7].Therefore, identification of the mechanisms involved in the progression to CRPC is important for the development of novel effective therapies.

\footnotetext{
Conflict of interest: None.

*Correspondence to: Osamu Ogawa MD, PhD, 53 Kawahara-cho, Sakyo-ku, Shogoin, Kyoto, Japan.

E-mail: ogawao@kuhp.kyoto-u.ac.jp

Received 17 December 2013; Accepted 16 July 2014

DOI 10.1002/pros.22877

Published online in Wiley Online Library

(wileyonlinelibrary.com).
} 
We have established a novel prostate cancer xenograft model, KUCaP-2. KUCaP-2 tumors are derived from locally recurrent CRPC specimens, harbor wildtype AR and express PSA [8]. Using this model, we previously reported gene expression profiles that correspond to the transition to CRPC. In this model, tumors regress soon after castration, but then reproducibly restore their ability to proliferate after 1-2 months, mimicking the clinical behavior of CRPC. In order to investigate the role of microRNAs in the progression of CRPC, we evaluated expression profiles by microarray analysis of microRNAs derived from xenograft tumor tissues obtained at the CRPC stage in comparison to those at an androgen dependent stage. A total of 173 microRNAs were significantly over-expressed at the CRPC stage in the xenograft model. With long term culturing under androgen-deprived conditions, we have also established a mutant counterpart of LNCaP cells, AILNCaP\#1 cells, which can proliferate under androgen-deprived conditions. Using both transition models, miR-582-5p was reproducibly up-regulated in androgen independent states in comparison to androgen dependent counterpart. Therefore, we analyzed the contribution of miR-582-5p to the regulation of prostate cancer cell proliferation under androgen-deprived conditions by over-expressing or reducing miR$582-5 p$ expression in LNCaP cells or AILNCaP\#1 cells respectively. Moreover, we found that miR-582-5p directly targeted EFNB2 expression, which has been shown to be down-regulated in CRPC (Oncomine database). Taken together, our results suggest that miR582-5p may contribute to the development of CRPC and may be a target for therapeutic development.

\section{MATERIAL AND METHODS}

\section{Cell Cultures}

The prostate cancer cell line, $\mathrm{LNCaP}$, was obtained from the American Type Culture Collection (Rockville, $\mathrm{MD})$. LNCaP cells were cultured routinely in RPMI (Invitrogen, Carlsbad, CA) supplemented with 10\% FBS at $37^{\circ} \mathrm{C}$ in incubators with humidified air and 5\% carbon dioxide. The subline, AILNCaP\#1, was established using the same approach as described previously [9], and was maintained in phenol red-free RPMI supplemented with $10 \%$ CSFBS.

\section{Cell Proliferation and Cell Cycle Analysis}

For cell counting, target cells were inoculated into $6 \mathrm{~cm}$ dishes at $25 \times 10$ cells/plate. After allowing $24 \mathrm{hr}$ incubation for cell adhesion, the number of cells was determined as baseline on day 0 and thereafter on days 2,4 , and 6 . Cells were collected by trypsinization and counted using a hemocytometer. In the cell proliferation assay, $75 \times 10^{3}$ cells $/ 100 \mu \mathrm{l}$ culture medium were seeded on each well of 96-well plates and cultured for $48 \mathrm{hr}$ and $96 \mathrm{hr}$. Then, $10 \mu \mathrm{l} /$ well Cell Proliferation Reagent Cell Counting Kit-8 (Dojindo Laboratories, Kumamoto, Japan) was added and incubated for $1 \mathrm{hr}$, and the absorbance of the formazan product formed was detected at 450 and $650 \mathrm{~nm}$ with a 96-well spectrophotometric plate reader. Cell cycle was examined with fluorescence-activated cell sorting (FACS) as described previously [9].

\section{Microarray Analysis and Real-time PCR}

Small RNAs were extracted from cultured cells using the mirVana ${ }^{\mathrm{TM}}$ miRNA Isolation Kit (Applied Biosystems, Foster City, CA) and cDNA was synthesized from $500 \mathrm{ng}-1 \mu \mathrm{g}$ small RNAs using the miScript RT Kit (Qiagen, Valencia, CA) according to the manufacturer's protocols. Total RNA was isolated and purified using the RNeasy Mini Kit (Qiagen, Valencia, CA). Changes in miRNA expression were analyzed using TORAY 3D-Gene Human miRNA microarray ver.12.1. After quantile normalization, we evaluated the results by $t$-test $(P<0.05)$ and fold changes $(>2.5$ fold) to select candidate microRNAs. Gene expression changes in miR-582-5p transfectants were analyzed using DNA microarray with GeneChip ${ }^{\mathbb{R}}$ Human Gene 1.0 ST array and data mining software (GeneSpring GX Version11.5.1). PCR was performed by miScript SYBR Green PCR Kit (Qiagen, Valencia, CA) using the Delta-Delta Ct method as previously described [10]. The values were normalized to the amount of the snRNA RNU6B.

\section{Transient miRNA and mi RNA Inhibitor Transfection}

Pre-miR-582-5p precursor, anti-miR-582-5p miRNA inhibitor, precursor negative control and inhibitor negative control were purchased from Ambion Inc. (Austin, TX). The cells were transfected with $30 \mathrm{nM}$ of precursors or inhibitors in serum free conditions using siPORT ${ }^{\mathrm{TM}}$ NeoFX ${ }^{\mathrm{TM}}$ Transfection Agent according to the manufacturer's protocols. After transfection, the cells were seeded into 96-well plates for cell proliferation assays.

\section{Generation of Stable Clones Expressing miR-582- $5 p$ or Anti-microRNA Against miR-582-5p}

The lentiviral vector expressing miR582-5p (PMIRH582PA-1), the lentiviral vector for miRZip anti-sense microRNA against miR-582-5p (MZIP582$5 \mathrm{p}-\mathrm{PA}-1)$ and control vectors were purchased from SBI (Mountainview, CA). Each of these vectors and pack- 
aging plasmid mix (LV500A-1, SBI) were co-transfected into 293T cells. After $48 \mathrm{hr}$, pseudoviral particles in the supernatant were collected and concentrated by centrifuge for $24 \mathrm{hr}$. After infecting target cells with the pseudovirus containing supernatant, infected cells expressing miR-582-5p were selected by FACS sorting. miRZip infected cells were selected using puromycin for 2 weeks.

\section{Prediction of microRNA Targets}

To confirm the sequences of microRNAs, miRBase (http://www.microna.org) was utilized. The target genes of microRNAs were predicted by referring to Targetscan (http:/ /www.targetscan.org).

\section{Luciferase Reporter Assay}

We used Duo-Luciferase reporter vector pEZXMT01 (Genecopoeia, Rockville, MD) as a luciferase vector. Custom 3'UTR miRNA target clones for $\mathrm{Hu}-$ man EFNB2 in pEZX-MT01 (EFNB2-01, EFNB2-02) were purchased from Genecopoeia (Rockville, MD). EFNB2-01 and EFNB2-02 contain 3'UTR of EFNB2 position 2653-2682 and position 2967-2996, respectively. LNCaP cells were cotransfected with Duo-Luciferase reporter vector and Pre-miR-582-5p precursor or negative control. Cells were harvested $48 \mathrm{~h}$ after transfection and assayed with LucPair ${ }^{\mathrm{TM}}$ Duo-Luciferase Assay Kit (Genecopoeia, Rockville, MD) according to the manufacturer's protocols.

\section{Western Blotting}

Western bloting was performed with each primary antibody (AR, 1:400; PSA, 1:400; EFNB2, 1:250; $\beta$-actin, $1: 5,000)$ as previously reported [9]. EFNB2 antibody (HPA008999) was purchased from Sigma-Aldrich (St. Louis, MO). AILNCaP\#1 cells were collected $48 \mathrm{~h}$ after anti-miR-582-5p miRNA inhibitor or negative control transfection for protein extraction and analysis as previously described [9].

\section{RESULTS}

\section{Changes in microRNA Expression Profiles With Transition to Castration Resistant Stage in KUCaP2 Xenograft Models}

In order to investigate the role of microRNAs in the progression of CRPC, we evaluated expression profiles of microRNAs derived from the KUCaP2 xenograft tumor tissues at the CRPC stage in comparison to those at the androgen dependent (AD) stage $(n=4)$ by microRNA microarray analysis. The data have been deposited in GEO database (http://www.ncbi. nlm.nih.gov/geo/query/acc.cgi?acc=GSE55829). One hundred seventy three microRNAs were significantly over-expressed $(P<0.05)$ at the CRPC stage, six of which (miR-374b, miR-582-5p, miR-101, miR-429, miR100 , and miR-32) were up-regulated at the CRPC stage by $>2.5$-fold (Table I). Only three microRNAs (miR451, miR-486-5p, and miR-145*) were significantly down-regulated at the CRPC stage. To validate the results, we evaluated expression of the six microRNAs by real-time PCR (Fig. 1). The PCR analysis confirmed that each of the six microRNAs was up-regulated at the CRPC stage in comparison to AD stage.

\section{miR-582-5p Expression was Up-regulated in AILNCaP \# I Cells in Comparison With LNCaP Cells}

In order to select miRNA candidates that might participate in the transition to CRPC, we evaluated expression levels of those microRNAs in the androgen-dependent cell line, $\mathrm{LNCaP}$ and the androgenindependent cell line, AILNCaP\#1 utilizing real-time PCR. AILNCaP\#1 cells are able to proliferate under androgen-deprived conditions and express the androgen receptor but do not express PSA (Fig. 2A,B). MiR-582-5p was the only miRNA over-expressed in AILNCaP\#1 cells among the six microRNAs studied (Fig. 2C).

\section{MiR-582-5p Contributed to Prostate Cancer Cell Proliferation Under Androgen Deprived Condition}

To investigate the role of miR-582-5p in prostate cancer cell proliferation under androgen deprived conditions, we performed cck-8 assays using transiently over-expressing or under-expressing miR-582-5p. The results revealed that transient transfection of the miR-582-5p precusor significantly increased the

TABLE I. Upregulated microRNAs Derived From Microarray Analysis

\begin{tabular}{lcc}
\hline microRNA & $\begin{array}{c}P \text { value } \\
(t \text { test AD vs. CR })\end{array}$ & $\begin{array}{c}\text { fold change } \\
(\log 2) \text { CR/AD }\end{array}$ \\
\hline hsa-miR-374b & 0.0058 & 3.53 \\
hsa-miR -582-5p & 0.0236 & 3.48 \\
hsa-miR - 101 & 0.0228 & 2.97 \\
hsa-miR -429 & 0.0009 & 2.55 \\
hsa-miR - 100 & 0.0096 & 2.51 \\
hsa-miR-32 & 0.0123 & 2.5 \\
\hline
\end{tabular}

$\mathrm{AD}$, androgen-dependent growth stage. $\mathrm{CR}$, castration-resistant regrowth stage. 

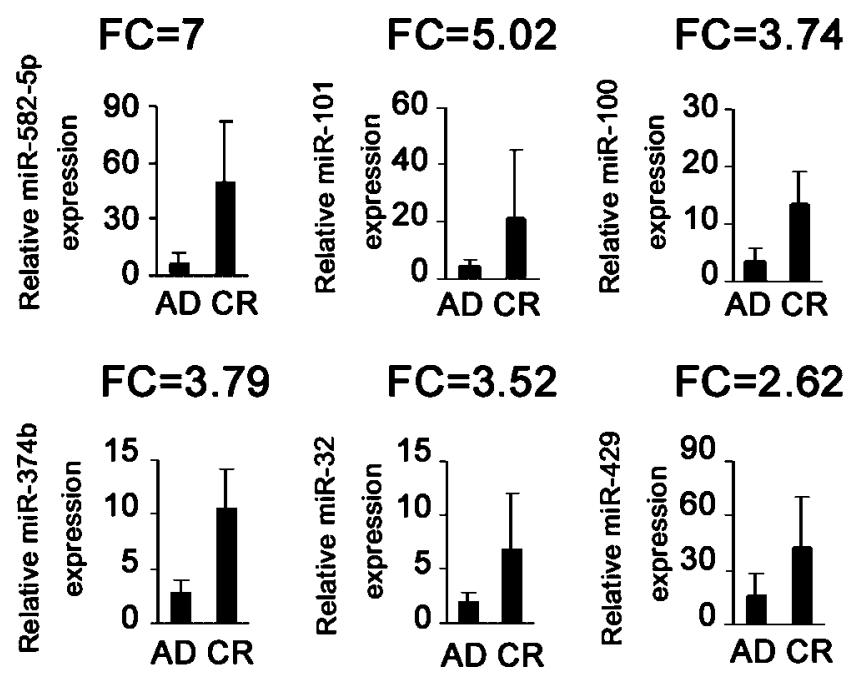

Fig. I. Validation of microRNA expression profiles of KUCaP2 xenograft models. Real- time PCR revealed that six microRNAs (miR-374b, miR-582-5p, miR-I0I, miR-429, miR-I00, and miR-32) were up-regulated in CRPC stage. FC means fold change (log2). Each bar represents the mean \pm SD of four xenograft tissues.

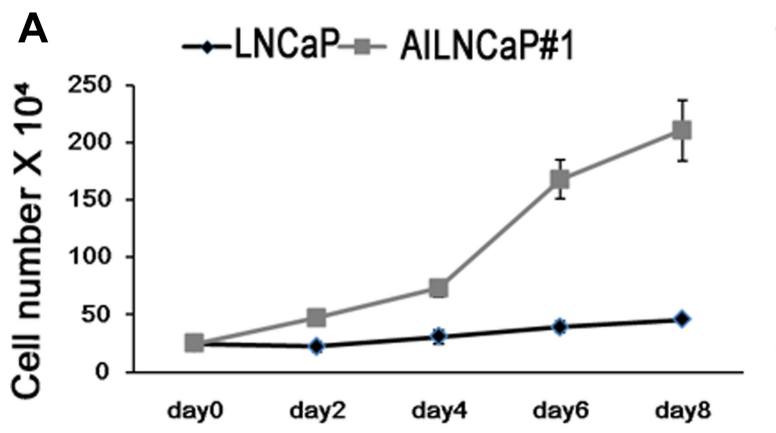

B
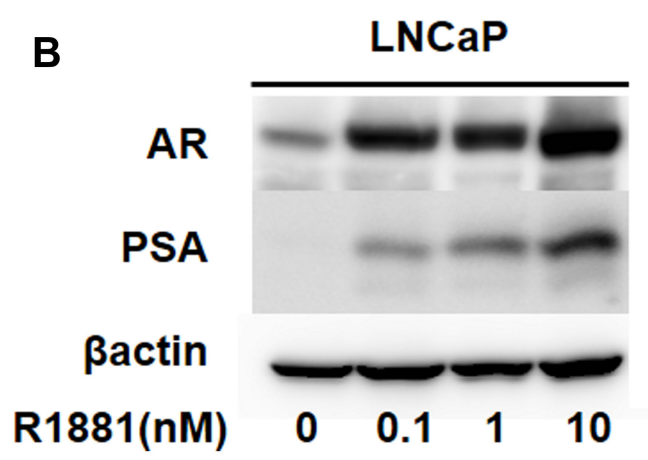

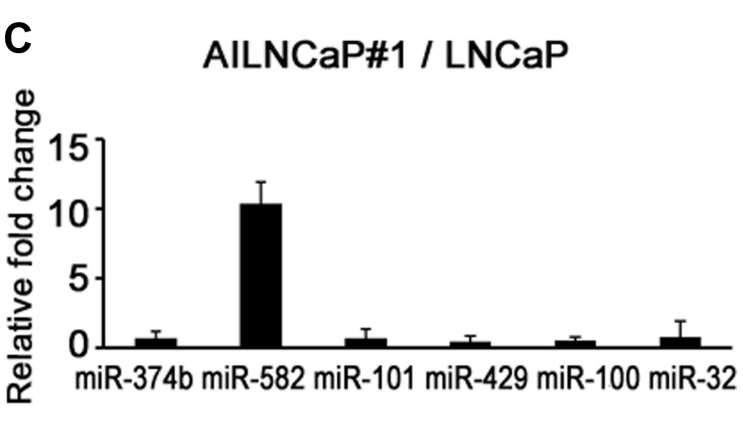

AILNCaP\#1

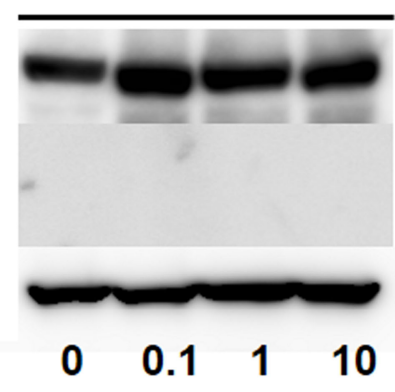

Fig. 2. AILNCaP\#I cells can proliferate under androgen deprived conditions. miR-582-5p expression was up-regulated in AILNCaP\#I cells in comparison with LNCaP cells. (A) For cell counts, cells were inoculated into $6 \mathrm{~cm}$ dishes at $25 \times 10^{4}$ cells/plate in phenol red-free RPMI $+10 \%$ CSFBS. After $24 \mathrm{hr}$ incubation for cell adhesion, the number of cells was counted as baseline on day 0 and thereafter on days $2,4,6$, and 8. Cells were collected by trypsinization and counted using a hemocytometer. (B) Western blotting analysis of AR and PSA expression in AILNCaP\# I cells. LNCaP cells were used as a positive control. $\beta$-actin was used as a loading control. After cultured in androgen deprivation for $96 \mathrm{hr}$, LNCaP cells were treated with the indicated dose of RI88I for $24 \mathrm{hr}$. AlLNCaP\# I cells were cultured in phenol red-free RPMI + I0\% CSFBS for $48 \mathrm{hr}$ and cultured with the indicated dose of RI88I for $24 \mathrm{hr}$. (C) MicroRNA expression levels in the castration-resistant cell line AILNCaP\# I assessed by real-time PCR. Each bar represents the mean \pm SD of three independent experiments. 

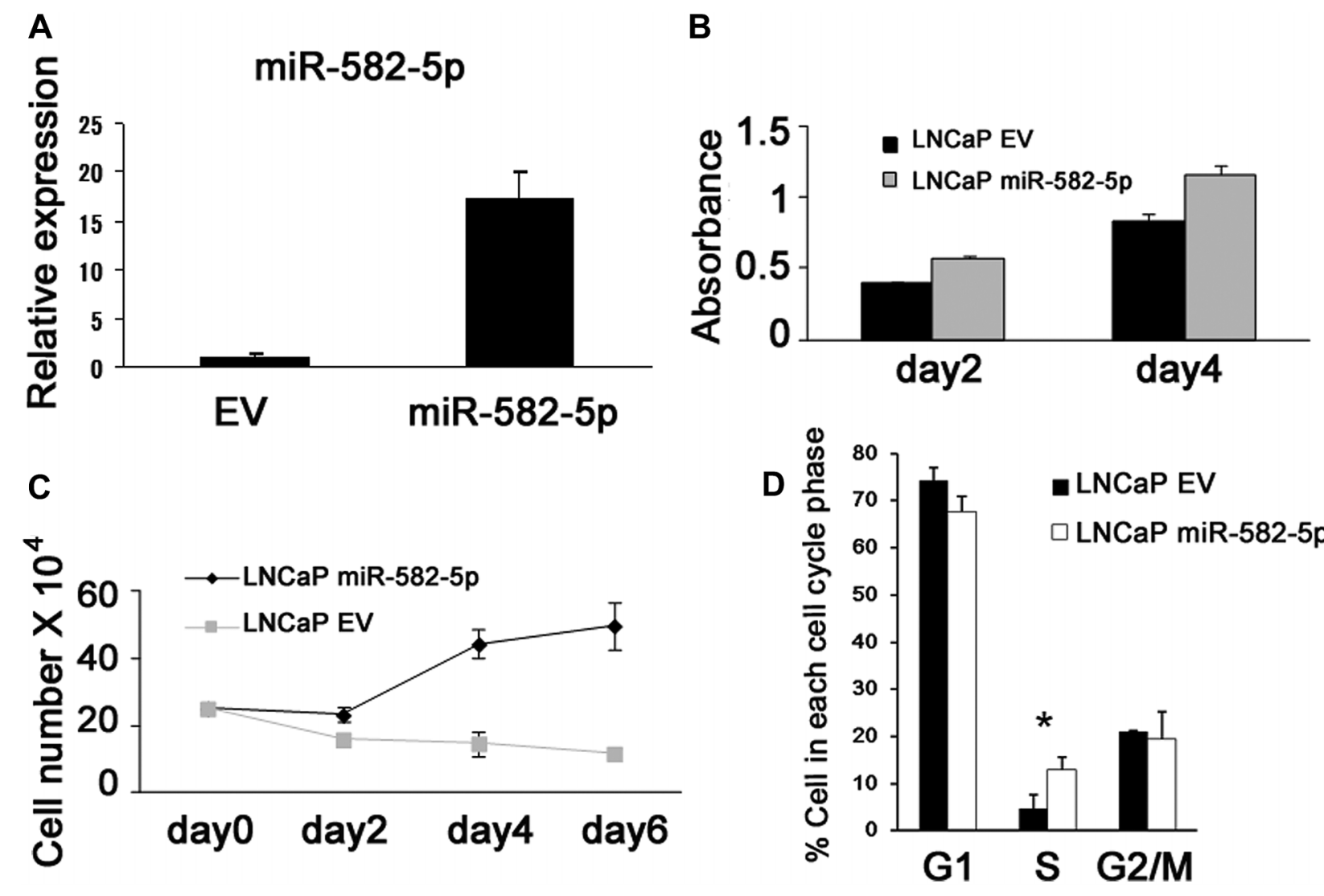

Fig. 3. miR-582-5p contributes to prostate cancer cell proliferation under androgen-deprived conditions. (A) Real time PCR revealed that stable transfection with miR-582-5p precursor ( $\mathrm{LNCaP}$ miR-582-5p) was verified to be 17 -fold expression levels compared with empty vector (EV) groups. (B) $75 \times 10^{3}$ cells $/ 100$ ul culture medium seeded on each well of 96 -well plates and cultured for $48 \mathrm{hr}$ and $96 \mathrm{hr}$ under androgen deprived conditions. Then, $10 \mathrm{ul} /$ well Cell proliferation Reagent Cell Counting Kit-8 (Dojindo Laboratories, Japan) was added and incubated for $\mathrm{Ihr}$ and the absorbance of the formazan product formed was detected at 450 and $650 \mathrm{~nm}$ with a 96 -well spectrophotometric plate reader. All experiments were repeated two or three times. Data in a panel revealed the representative result among three independent experiments. (C) LNCaP miR-582-5p and LNCaP EV cells were inoculated into $6 \mathrm{~cm}$ dishes at $25 \times 10^{4}$ cells/plate. After $24 \mathrm{hr}$ incubation for cell adhesion, the number of cells was counted as baseline on day 0 and thereafter on days 2,4 , and 6 . Cells were collected by trypsinization and counted using a hemocytometer. Data in a panel revealed the representative result between two independent experiments. Each bar represents the mean \pm SD. (D) Cell cycle was examined with fluorescence-activated cell sorting. After $24 \mathrm{hr}$ in RPMI $+10 \% \mathrm{FBS}$ for $24 \mathrm{hr}$, LNCaP mir-582-5p, and LNCaP EV cells were inoculated in phenol-red free RPMI + CSFBS for $48 \mathrm{hr}$. Each bar represents the mean \pm SD of three independent experiments. * indicates $P<0.05$.

pressed cell proliferation of AILNCaP\#1 cells under androgen deprived conditions (Figs. 4B,C and D). These results demonstrate that, at least in $\mathrm{LNCaP}$ cell model, miR-582-5p may contribute to the transition to androgen independent cell proliferation.

\section{MiR-582-5p Reduced the Expression Level of EFNB2}

To investigate targets of miR-582-5p that which might participate in the transition to CRPC, we evaluated the gene expression profiles of LNCaP miR582-5p cells and LNCaP EV cells using DNA microarray analysis. The data have been deposited in GEO database (http://www.ncbi.nlm.nih.gov/geo/query/ acc.cgi?acc $=$ GSE56669). We also compared the results with gene expression profiles of the KUCaP2 CRPC model previously described [8]. Thirteen genes were down-regulated both in LNCaP miR-582-5p cells and in KUCaP2 CRPC stage. Six of these 13 genes are predicted to have target sites for miR-582-5p in their 3'UTR by Targetscan (www.targetscan.org) (Table II). According to a published database, expression levels of EFNB2, a member of the ephrin family that has been described as mediating developing, were significantly decreased in CRPC compared to hormone-naïve prostate cancer (Fig. 5A) [11]. There were no published data regarding the other five genes, which revealed 
A

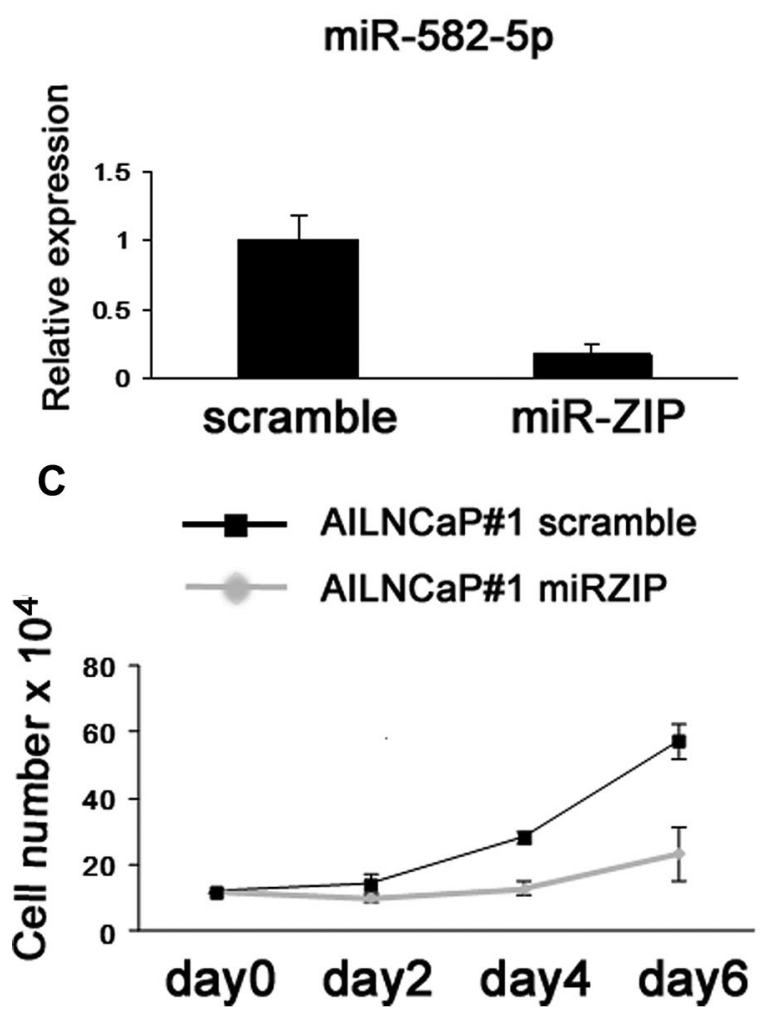

B - AILNCaP\#1 scramble

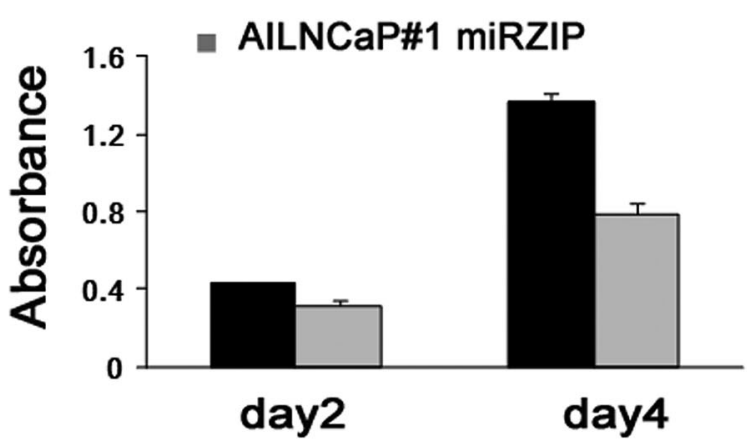

D

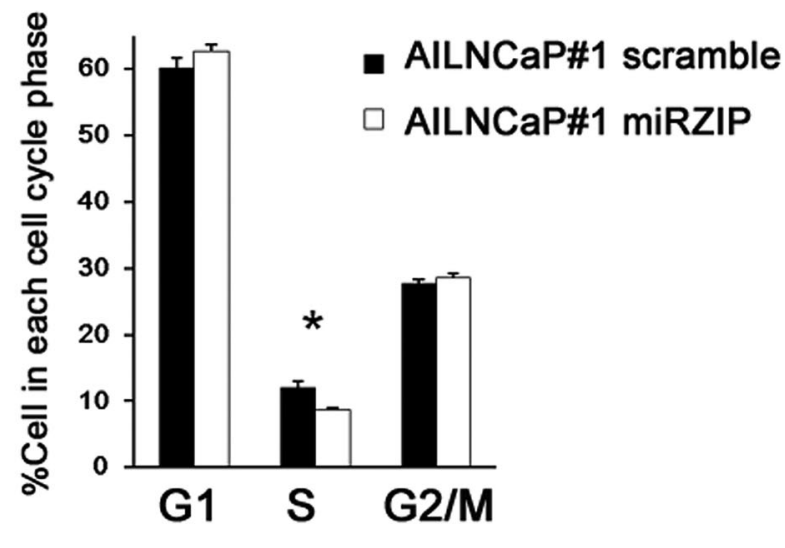

Fig. 4. Reduction of miR-582-5p expression suppressed cell proliferation of AILNCaP\#I cells. (A) Real time PCR revealed that stable transfection with miR-582-5p inhibitor (miR-ZIP) was verified to be 0.17 -fold expression levels of miR-582-5p compared with scramble vector (scramble) groups. (B) $75 \times 10^{3}$ cells $/ 100$ ul culture medium seeded on each well of 96 -well plates and cultured for $48 \mathrm{hr}$ and $96 \mathrm{hr}$ under androgen-deprived condition. Then, $10 \mathrm{ul} /$ well Cell proliferation Reagent Cell Counting Kit- 8 was added and incubated for Ihr, and the absorbance of the formazan product formed was detected at 450 and $650 \mathrm{~nm}$ with a 96 -well spectrophotometric plate reader. Data in a panel revealed the representative result among three independent experiments. (C) AILNCaP miR-ZIP and AILNCaP scramble cells were inoculated into $6 \mathrm{~cm}$ dishes at $12 \times 10^{4}$ cells/plate. After $24 \mathrm{hr}$ incubation for cell adhesion, the number of cells was counted as baseline on day 0 and thereafter on days 2,4 , and 6 . Cells were collected by trypsinization and counted using a hemocytometer. Data in a panel revealed the representative result between two independent experiments. Each bar represents the mean $\pm S D$. (D) Cell cycle was examined with fluorescence-activated cell sorting. After growth in phenol-red free RPMI $+10 \%$ CSFBS for $48 \mathrm{hr}$, miR-ZIP and scramble cells were harvested by trypsinization. Each bar represents the mean \pm SD of three independent experiments. * indicates $P<0.05$.

that those genes were down regulated in CRPC. Targetscan revealed that EFNB2 contains two potential target sites for miR-582-5p in its $3^{\prime}$ UTR (Fig. 5B). Luciferase assay revealed that miR-582-5p decreased the luciferase activity of reporter vectors containing putative biniding site in the $3^{\prime}$ UTR of EFNB2 (Fig. 5C). These results support Targetscan prediction indicating the $3^{\prime}$ UTR of EFNB2 as a target of miR-582-5p. We evaluated the expression level of EFNB2 at the mRNA levels, in LNCaP miR-582-5p cells using real time PCR. EFNB2 was significantly down regulated in LNCaP miR-582-5p cells in comparison with LNCaP EV cells under androgen-deprived conditions (Fig. 5D). Western blotting analysis showed that miR-582-5p decreased EFNB2 expression level in LNCaP cells, and transient transfection of anti-miR-582-5p increased EFNB2 expression level in AILNCaP\#1 (Fig. 5E). These findings denote that miR-582-5p negatively regulates the expression of EFNB2.

\section{DISCUSSION}

A number of studies have shown that expression levels of microRNAs are dysregulated in prostate cancer and several microRNAs can act oncogenically or as a tumor suppressor in prostate cancer cell lines $[6,12-15]$. Several microRNAs have been reported to induce prostate cancer cell proliferation under 
TABLE II. Downregulated Genes Derived From Microarray Analysis

\begin{tabular}{lcr}
\hline & LNCaP & \\
Gene Symbol & miR-582-5p/LNCaP EV & CR/AD \\
\hline EFNB2 & -2.697 & -2.004 \\
RAB27A & -1.787 & -2.615 \\
MBOAT2 & -1.878 & -2.281 \\
AFF3 & -2.225 & -1.219 \\
SLC4A4 & -3.109 & -0.546 \\
CAP2 & -1.629 & -0.744 \\
\hline
\end{tabular}

Fold change ( $\log 2)$.

androgen-deprived conditions [6,13-15]. These findings suggest that microRNA may have an important role in the development and regulation of CRPC.

In this study, we identified miR-582-5p to be upregulated both in the CRPC stage of the KUCaP2 model and in an androgen-independent cell line, AILNCaP\#1 in comparison with the controls. Furthermore, cell proliferation and cell cycle analyses revealed that over expression of miR-582-5p induced LNCaP cell proliferation in androgen-deprived conditions and that reducing the expression of miR-582-5p suppressed AILNCaP\#1 cell proliferation. These results demonstrated that at least in our independent models, miR582-5p might participate in the transition to CRPC. In order to investigate miR-582-5p expression in other androgen-independent prostate cancer cells, we also evaluated its expression in PC3 and DU145 cells. The expression levels observed in the PC3 cells was comparable to that of LNCaP, but that of DU145 was less than $1 / 5$ of LNCaP (data not shown). Thus AILNCaP\#1 expressed extremely high level of miR582-5p in comparison to that of PC3 and DU145 cells. Taken together, these data showed that over expression of miR-582-5p might contribute to transition of androgen-receptor positive, androgen-dependent cells
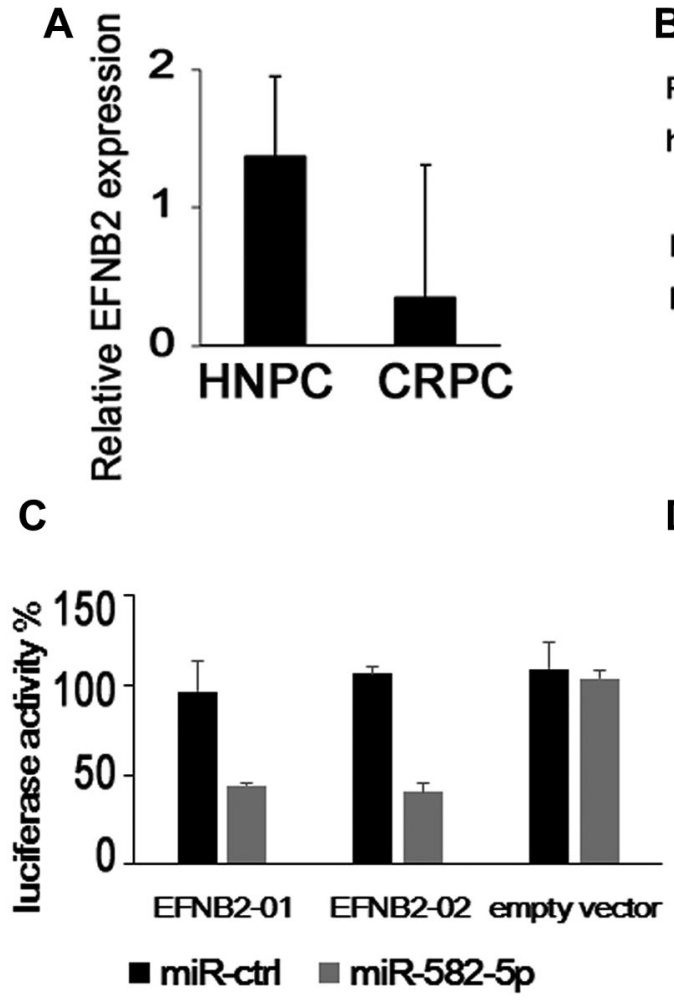

B

\begin{tabular}{|c|c|}
\hline Position $2675-2681$ of $3^{\prime}$ UTR & 5'--UAGCUUUGGAAAGUUACUGUAAA--- 3' \\
\hline hsa-miR-582-5p & 3' UCAUCGACCAACUUGUUGACAUU \\
\hline Position $2989-2995$ of 3 'UTR & 5' -.-GUCAUUCCCCUUUGCACUGUAAU.-. 3' \\
\hline hsa-miR-582-5p & 3' UCAUCGACCAACUUGUUGACAUU \\
\hline
\end{tabular}

$\mathbf{E}$

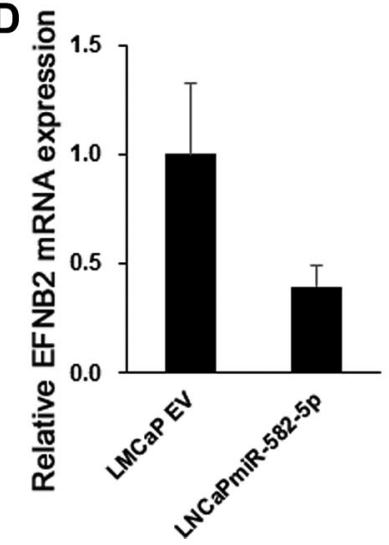

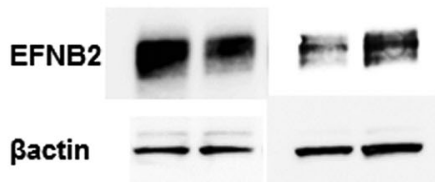

EV miR Ctrl anti

Fig. 5. MiR-582-5p reduced the expression levels of EFNB2 mRNA and protein. (A) A database published by Tomlins et al. [II] showed that mRNA level of EFNB2 was significantly decreased in CRPC compared to that in hormone-näve prostate cancer (HNPC) $P<0.05$. (B) There are two miR-582-5p potential binding sites in the 3UTR of EFNB2. (C) EFNB2-01 or EFNB2-02 luciferase constructs containing a potential binding site of position $2675-268$ I or of position 2989-2995 representatively were transfected into LNCaP cells with miR-582-5p or negative control. Luciferase activity was determined $24 \mathrm{hr}$ after transfection. Each bar represents the mean \pm SD of three independent experiments. (D) Real-time PCR analysis of EFNB2 expression in LNCaP EV and LNCaP miR-582-5p. Each bar represents the mean \pm SD of three independent experiments. $P<0.05$ (E) Western blotting analysis of EFNB2 expression. LNCaP EV is represented as EV, LNCaP miR582-5p as miR, AlLNCaP\#I ctrl as Ctrl, and AILNCaP\#I anti-miR-582-5p as anti. 
to androgen-independent counterpart, but however, cellular proliferation of androgen receptor negative cells, such as PC3 and DU145, might fundamentally depend upon other mechanisms rather than overexpression of miR-582-5p. [16]

To our knowledge, this is the first report related to the expression of miR-582-5p in prostate carcinoma. In other cancer types, Uchino et al. recently demonstrated that miR-582-5p and $-3 p$ reduced cell proliferation and invasion of UM-UC-3 human bladder cancer cells [17]. Apparently contrary findings by Ya-Ching Lu et al. describe that miR-582-5p was significantly upregulated in oral cancers [18]. Amir et al. reported that miR-125b acts as an oncogene, which regulates p14 (ARF)/Mdm2 in prostate cancer [19], however, Feliciano reported that miR-125b acts as a tumor suppressor in breast tumorigenesis via the direct targeting of ENPEP, CK2- $\alpha$, CCNJ, and MEGF9 [20]. MiR-96 has been reported to be up regulated in prostate cancer and to enhance cellular proliferation of prostate cancer cells [21]. Contrary, in T-cell lymphoma cell line and non-small-cell lung cancer cell line, miR-96 decreases proliferation, colony formation, and migration of cancer cells [22]. All these reports suggested that certain miRNAs (oncomiRs) could act as tumor suppressors or as oncogenes according to the distinct types of cancers being studied.

The androgen receptor (AR) plays a crucial role in the development of prostate cancer and in the progression to CRPC $[7,23,24]$. Despite the importance of the $\mathrm{AR}$ in regulating prostate cancer cells, western blotting analysis showed that introduction of miR-582-5p to LNCaP cells did not affect the expression levels of AR and correspondingly, prostate specific antigen (PSA) (data not shown). These findings suggest that AR may not contribute to the transition to the castrationresistant cell proliferation regulated by miR-582-5p in LNCaP/AILNCaP\#1 transition model.

Our study supported that EFNB2 is a direct target of miR-582-5p at least in our LNCaP/AILNCaP\#1 transition model. EFNB2 has a highly conserved miR582-5p binding site in its $3^{\prime} \mathrm{UTR}$, and luciferase activity of EFNB2 3'UTR reporter vector was reduced by the transduced expression of miR-582-5p. Moreover, overexpression of miR-582-5p reduced both mRNA and protein expression levels of EFNB2 in LNCaP cells. Furthermore, the reduction of miR-582-5p enhanced EFNB2 protein level in AILNCaP\#1 cells. The EFN family are cell surface ligands of the EPH family receptor kinases, and reverse signaling from receptors to ligands is also known to be involved in cell-cell interactions and compartmentalization [25]. Rutkowski et al. reported that over expression of EphB4 confers a transformed phenotype in the case of MCF$10 \mathrm{~A}$ cells and an increased metastatic phenotype in the case of 22Rv1 cancer cells and that both phenotypes can be restrained by stimulation with EFNB2. The authors concluded from their studies that EFNB2dependent signaling through EphB4 may act as a tumor suppressor especially in cancer cells that express EphB4 [26]. Moreover, Noren et al. reported that EFNB2 reduced cell growth in MDA-MB-435 breast cancer cells [27]. Therefore, the down-regulation of EFNB2 by miR-582-5p may contribute to the acceleration of prostate cancer cell proliferation. To confirm the function of EFNB2 in cell proliferation under androgen deprived conditions, we suppressed the expression of EFNB2 in LNCaP cells using siRNA targeting EFNB2. In our studies, the Cck-assays revealed that transient knockdown of EFNB2 did not influence the proliferation of LNCaP cells under androgen-deprived conditions (data not shown). Therefore, mere downregulation of EFNB2 was not sufficient for transition to cell proliferation under androgen-deprived conditions in LNCaP cells. In addition to EFNB2, other targets of miR582-5p might participate in cell proliferation of $\mathrm{LNCaP}$ cells in an androgen -deprived environment. We also tried to overexpress EFNB2 in AILNCaP\#1 cells. However, it was difficult to produce cells overexpressing EFNB2. One additional complexity to our studies is that LNCaP cells express a mutated AR, which might influence the findings in that model system.

In summary, our results suggest that up-regulation of miR-582-5p contributes to an increase in the proliferation of prostate cancer cells under androgen deprived conditions. Further research is needed to analyze the mechanisms of miR-582-5p mediated development of CRPC, as well as ways in which these findings can be utilized for therapeutic approaches.

\section{ACKNOWLEDGMENTS}

We thank Dr. Yosuke Shimizu and Takeshi Yoshikawa for helpful advice. We also thank all members of Cancer Research Course in Graduated Courses and the Ogawa's lab for helpful discussion (Kyoto University, Graduate School of Medicine). We thank the skillful technical assistance of Miyuki Ono (Department of Urology, Kyoto University). This work was supported by a Grant-in Aid from Ministry of Education, Culture, Sports, Science and Technology.

\section{REFERENCES}

1. Calin GA, Croce CM. MicroRNA signatures in human cancers. Nat Rev Cancer 2006;6:857-866.

2. Esquela-Kerscher A, Slack FJ. Oncomirs - microRNAs with a role in cancer. Nat Rev Cancer 2006;6:259-269. 
3. Dalmay T, Edwards DR. MicroRNAs and the hallmarks of cancer. Oncogene 2006;25(46):6170-6175.

4. Porkka KP, Pfeiffer MJ, Waltering KK, Vessella RL, Tammela TL, Visakorpi T. MicroRNA expression profiling in prostate cancer. Cancer Res 2007;67:6130-6135.

5. Ribas J, Ni X, Haffner M, Wentzel EA, Salmasi AH, Chowdhury WH, Kudrolli TA, Yegnasubramanian S, Luo J, Rodriguez R, Mendell JT, Lupold SE. miR-21: An androgen receptor-regulated microRNA that promotes hormone-dependent and hormoneindependent prostate cancer growth. Cancer Res 2009;69:71657169 .

6. Ma S, Chan YP, Kwan PS, Lee TK, Yan M, Tang KH, Ling MT, Vielkind JR, Guan XY, Chan KW. MicroRNA-616 induces androgen-independent growth of prostate cancer cells by suppressing expression of tissue factor pathway inhibitor TFPI-2. Cancer Res 2011;71(2):583-592.

7. Inoue T, Kobayashi T, Terada N, Shimizu Y, Kamoto T, Ogawa O, Nakamura E. Roles of androgen-dependent and -independent activation of signal transduction pathways for cell proliferation of prostate cancer cells. Expert Rev Endocrinol Metab 2007;2:689704.

8. Terada N, Shimizu Y, Kamba T, Inoue T, Maeno A, Kobayashi T, Nakamura E, Kamoto T, Kanaji T, Maruyama T, Mikami Y, Toda Y, Matsuoka T, Okuno Y, Tsujimoto G, Narumiya S, Ogawa O. Identification of EP4 as a potential target for the treatment of castration-resistant prostate cancer using a novel xenograft model. Cancer Res 2010;70(4):1606-1615.

9. Inoue T, Yoshida T, Shimizu Y, Kobayashi T, Yamasaki T, Toda Y, Segawa T, Kamoto T, Nakamura E, Ogawa O. Requirement of androgen-dependent activation of protein kinase C $\zeta$ for androgen-dependent cell proliferation in LNCaP Cells and its roles in transition to androgen-independent cells. Mol Endocrinol 2006;20:3053-3069.

10. Ameya D, Jessica C, Angelica L. How to choose a normalization strategy for miRNA quantitative real-time (qPCR) arrays. J Bioinfo and Compu Bio 2011;9:795-812.

11. Tomlins SA, Mehra R, Rhodes DR, Cao X, Wang L, Dhanasekaran SM, Kalyana-Sundaram S, Wei JT, Rubin MA, Pienta KJ, Shah RB, Chinnaiyan AM. Integrative molecular concept modeling of prostate cancer progression. Nat Genet 2007;39(1):41-51.

12. $\mathrm{Wu} \mathrm{Z}, \mathrm{He} \mathrm{B}, \mathrm{He} \mathrm{J}$, Mao X. Upregulation of miR-153 promotes cell proliferation via downregulation of the PTEN tumor suppressor gene in human prostate cancer. Prostate 2013;73(6): 596-604.

13. Sun T, Wang Q, Balk S, Brown M, Lee GS, Kantoff P. The role of microRNA-221 and microRNA-222 in androgenindependent prostate cancer cell lines. Cancer Res 2009;69(8): 3356-3363.

14. Shi XB, Xue L, Yang J, Ma AH, Zhao J, Xu M, Tepper CG, Evans $\mathrm{CP}$, Kung $\mathrm{HJ}$, deVere White RW. An androgen-regulated miRNA suppresses Bak1 expression and induces androgen-independent growth ofprostate cancer cells. Proc Natl Acad Sci U S A 2007;104(50):19983-19988.

15. Qu F, Cui X, Hong Y, Wang J, Li Y, Chen L, Liu Y, Gao Y, Xu D, Wang Q. MicroRNA-185 suppresses proliferation, invasion, migration, and tumorigenicity of human prostate cancer cells through targeting androgen receptor. Mol Cell Biochem 2013;377(1-2):121-130.

16. Uzoh CC, Holly JM, Biernacka KM, Persad RA, Bahl A, Gillatt $\mathrm{D}$, Perks CM. Insulin-like growth factor-binding protein-2 promotes prostate cancer cell growth via IGF-dependent or -independent mechanisms and reduces the efficacy of docetaxel. Br J Cancer 2011;104(10):1587-1593.

17. Uchino K, Takeshita F, Takahashi RU, Kosaka N, Fujiwara K, Naruoka H, Sonoke S, Yano J, Sasaki H, Nozawa S, Yoshiike M, Kitajima K, Chikaraishi T, Ochiya T. Therapeutic effects of microRNA-582-5p and $-3 p$ on the inhibition of bladder cancer progression. Mol Ther 2013;21(3):610-619.

18. Lu YC, Chen YJ, Wang HM, Tsai CY, Chen WH, Huang YC, Fan $\mathrm{KH}$, Tsai CN, Huang SF, Kang CJ, Chang JT, Cheng AJ. Oncogenic function and early detection potential of miRNA-10b in oral cancer as identified by microRNA profiling. Cancer Prev Res (Phila) 2012;5(4):665-674.

19. Amir S, Ma AH, Shi XB, Xue L, Kung HJ, Devere White RW. Oncomir miR-125b suppresses p14(ARF) to modulate p53dependent and p53-independent apoptosis in prostate cancer. PLoS One 2013;8(4):e61064.

20. Feliciano A, Castellvi J, Artero-Castro A, Leal JA, Romagosa C, Hernández-Losa J, Peg V, Fabra A, Vidal F, Kondoh H, Ramón Y, Cajal S, Lleonart ME. miR-125b Acts as a Tumor Suppressor in Breast Tumorigenesis via Its Novel Direct Targets ENPEP, CK2- $\alpha$, CCNJ, and MEGF9. PLoS One 2013;8(10):e76247.

21. Haflidadóttir BS, Larne O, Martin M, Persson M, Edsjö A, Bjartell A, Ceder Y. Upregulation of miR-96 enhances cellular proliferation of prostate cancer cells through FOXO1. PLoS One 2013;8(8):e72400

22. Vishwamitra D, Li Y, Wilson D, Manshouri R, Curry CV, Shi B, Tang XM, Sheehan AM, Wistuba II, Shi P, Amin HM. MicroRNA 96 is a post-transcriptional suppressor of anaplastic lymphoma kinase expression. Am J Pathol 2012;180(5):1772-1780.

23. Wang Q, Li W, Zhang Y, Yuan X, Xu K, Yu J, Chen Z, Beroukhim R, Wang H, Lupien M, Wu T, Regan MM, Meyer CA, Carroll JS, Manrai AK, Jänne OA, Balk SP, Mehra R, Han B, Chinnaiyan AM, Rubin MA, True L, Fiorentino M, Fiore C, Loda M, Kantoff PW, Liu XS, Brown M. Androgen receptor regulates a distinct transcription program in androgen-independent prostate cancer. Cell 2009;138:245-256.

24. Feldman BJ, Feldman D. The development of androgen-independent prostate cancer. Nat Rev Cancer 2001;1:34-45.

25. Kataoka H, Tanaka M, Kanamori M, Yoshii S, Ihara M, Wang YJ, Song JP, Li ZY, Arai H, Otsuki Y, Kobayashi T, Konno H, Hanai H, Sugimura H. Expression profiles of EFNB1, EFNB2, two ligands of EPHB2 in human gastric cancer. J Cancer Res clin Oncol 2002;128:343-348.

26. Rutkowski R, Mertens-Walker I, Lisle JE, Herington AC, Stephenson SA. Evidence for a dual function of EphB4 as tumor promoter and suppressor regulated by the absence or presence of the ephrin-B2 ligand. Int J Cancer 2012;131(5):E614-E624.

27. Noren NK, Lu M, Freeman AL, Koolpe M, Pasquale EB. Interplay between EphB4 on tumor cells and vascular ephrin-B2 regulates tumor growth. Proc Natl Acad Sci U S A 2004;101(15):5583-5588 